\title{
A New Pattern for Economy, Utility and Beauty: The North Dakota Agricultural College Library
}

Mr. Stallings is librarian, North Dakota A gricultural College, Fargo.

To construct and equip, even on a 1 modest basis, a college library in the year I950 for eight-five cents a cubic foot is an accomplishment of great significance. Ever since the revival of interest in the Snead method of modular construction in I 943, cubic costs of this size have been discussed but not achieved. Thus, librarians and architects will now turn to the North Dakota Agricultural College to see how it can be done.

This building will be ready for occupancy late in the summer of I950. It contains two stories plus a full basement. Its dimensions are $115^{\prime} \times 160^{\prime}$, with a floor to floor dimension of IO' $^{\prime \prime}$ ". It contains 44,000 square feet and 550,000 cubic feet. The modules are $22^{\prime} 6^{\prime \prime}$ square. The sum of $\$ 500,000$ was available for the structure and equipment.

The firm of Wm. F. Kurke and Associates in Fargo were the architects and Snead \& Company supplied the steel structure. Equipment and furniture are being purchased from several firms.

The architectural style of the buildings on the North Dakota Agricultural College campus follows no single motif. Thus, the architects were free to design a library entirely from the inside out, without being required to mold the exterior shape to conform, with a resulting loss of economy, to something other than what the interior dictated. The beauty of the building thus derives from its complete truthfulness. But this is not the whole story. Without skillful architects to create good proportion, line and mass, the building would not be beautiful. And without skillful use of color and good furniture, the interior might be unpleasant. Fortunately, our achitects have had the necessary skill, and taste, and sense of design.

Lighting in the new building will be Louverall, which is expensive to install, but which in reality is not expensive when all costs are taken in to consideration.

Ventilation and heating is provided, using the Snead system, through the hollow columns and girders. Alternate columns supply and exhaust the air in each module. It is interesting that the steel structure was erected in 10 working days. The exterior walls are of brick and hollow tile separated by one inch of spun glass insulation. Flooring will be asphalt tile and furniture finish will be a light oak.

The first floor-35 modules-includes a lower division reading room-IO modules; a student lounge -3 modules; a stack area -8 modules; classroom-2 modules; staff lounge, seminars, conference rooms, halls, entrances, stairways and faculty studies -9 modules.

The second floor includes another reading room-8 modules; a periodical room -4 
modules; stack area- 6 modules; conference and seminar rooms -4 modules; staff lounge-I module; offices (order, catalog and periodical checking room) -5 modules; and halls, loan desk, card catalog, stairs and faculty lounge -8 modules.

Each reading room contains cubicles of the conventional type, tables of various shapes and reading room carrels. Some of the cubicles and reading room carrels will be soundproofed with cork to permit typing in the reading rooms. The library plans to rent typewriters.

Bookshelves in the reading rooms will not be dispersed around the walls, but instead will be concentrated, and the reference and reserve books will be located near the reserve and reference desks. The arrangement of furniture and equipment will be informal.

Future expansion will be both vertical and horizontal. Footings permit one full story to be added vertically, and adequate space exists for indefinite horizontal growth.

There is, of course, no one best way to build a library because local needs, traditions, and conditions vary. But where there is a minimum of restricting preconditions, we believe that librarians who need a maximum amount of usable and pleasant working space for each dollar invested, will find a desirable pattern in the library of the North Dakota Agricultural college.

As soon as the building is open for service in the fall of 1950, we invite visitors. In the meanwhile, much information on construction methods can be gained from an onthe-site inspection. Certainly, those who said "it can't be done" will have difficulty in explaining away that which they can see with their own eyes.

\section{Current Trends in the College Reserve Room}

\section{(Continued from page I24)}

has always been that this keeps reserve books close to the other material on the subject. This great faith in the classification scheme astounds me, and even if it were true that the reserve shelf actually lands in the midst of all the other important literature on the subject, I would still feel that this has no particular merit as the students do not have time to shuttle back and forth from reserve books to other books in the course of the day's reading. Last year approximately Io,000 volumes were on reserve during the year.

Like many other librarians, I view the reserve system with a jaundiced eye. In many cases, all that is established is an anthology which does not seem very far from a textbook to me. As our entire library is open shelf, we have no way of knowing how much individual books are used. I am willing to bet, however, that 50 per cent of the books would have served their purposes better from the regular shelves. Pressure does build up for a relatively small number of books and the control of these is extremely difficult. We cannot know about this pressure until the book has been stolen or hidden.

While I hate to revert to the old type of closed reserves, I do wish we could centralize our reserves on open shelves and establish a simple charging system for use in the building as well as for use overnight. ${ }^{13}$

13 The reserve systems of Stephens and Vassar are so atypical that no statistics for these two libraries have been included in this survey. 